http://jmscr.igmpublication.org/home/

ISSN (e)-2347-176x ISSN (p) 2455-0450

crossref DOI: https://dx.doi.org/10.18535/jmscr/v7i10.140

Journal Of Medical Science And Clinical Research

IGM Publication

An official Publication of IGM Publication

Original Research Article

\title{
Catheter Associated Urinary Tract Infection (CAUTI)- Incidence and Microbiological Evaluation in a Tertiary Care Hospital in Kota Region, an ICU Based Study
}

\author{
Authors \\ Dr Dinesh Verma ${ }^{1}$, Dr Anita Sharma ${ }^{2}$, Dr Ghanshyam Soni ${ }^{3}$, Dr Saurabh Sharma ${ }^{4 *}$ \\ ${ }^{1}$ Associate Professor, Department of Microbiology, Government Medical College, Kota \\ ${ }^{2}$ Senior Demonstrator Department of Microbiology, Government Medical College, Kota \\ ${ }^{3}$ Professor and Head, Department of Microbiology, Government Medical College, Kota \\ ${ }^{4}$ Assistant Professor, Department of Microbiology, Government Medical College, Kota \\ *Corresponding Author \\ Dr Saurabh Sharma
}

\begin{abstract}
Background: Catheter-associated urinary tract infections (CAUTIs) are the most common nosocomial infection affecting all age groups and are a leading cause of morbidity and mortality in hospitalized patients. The etiological agents are often multidrug resistant.

Objectives: 1. To find the incidence of CAUTI in intensive care unit (ICU) patients. 2. To identify etiological agents responsible for CAUTI. 3. To determine antimicrobial susceptibility pattern for bacterial agents obtained.

Methods: Urine samples from 210 clinically suspected cases of CAUTI were obtained from patients with urinary catheters admitted in ICUs. Urine samples were subjected to wet mount, culture and sensitivity testing. Responsible pathogens and their antimicrobial susceptibility pattern were obtained based on CSLI standards.

Results: The incidence of CAUTI in the present study was 16\%. Higher incidence of CAUTI (55\%) was found in male sex as compared to females (45\%). Incidence of CAUTI was found higher as the days of catheterisation increased. Most predominant etiological agents responsible for CAUTI were E.coli (69.69\%) followed by klebsiella species (15.15\%) .25\% isolates among Enterobacteriaciae were ESBL producing. Uropathogens isolated from CAUTI are more resistant to antimicrobials.

Conclusions \& Prevention: It is must to implement following strategy for reducing the risk of infection due to indwelling catheters: 1. reducing the duration of catheterization 2. early removal of catheters, 3 . aseptic insertion 4. maintenance of a closed urinary drainage system.5 Strict infection control measures.
\end{abstract}

\section{Introduction}

The term "catheter fever" was used for the first time in $1883^{[1]}$ and it has been 50 years since Beeson, et al., recognized the potential harms arising from urethral catheterization and penned an editorial to the American Journal of Medicine titled "The case against the catheter" $"$ [2]. Urinary tract infections (UTIs) are the most common type of nosocomial infections encountered in healthcare facilities accounting for $30-40 \%$ of nosocomial infections. ${ }^{[3,4]}$. $80 \%$ of nosocomial UTI are associated with an indwelling urinary 
catheter ie catheter-associated infections (CAUTIs). The duration of catheterization remains the most significant factor in predicting CAUTI and each day of catheterization increases the risk of CAUTI by $3 \%$ to $10 \% .^{[6,7]}$ Left undiagnosed and untreated, CAUTI increases the risk for complications and ultimately decreases the efficiency of health care delivery. Timely intervention is required to prevent complications such as cystitis, peri-uretheral abscess, prostatitis, epididymitis and acute or chronic pyelonephritis, bacteremia and urosepsis. ${ }^{[8]}$

Nearly $18 \%$ of patients with urinary tract related bacteremia have hospital acquired UTI and death from urosepsis is more likely in patients with CAUTI than in community acquired. ${ }^{[5,9]}$ This present study is undertaken to find out the prevalence of bacterial and fungal pathogens as a cause of CAUTI and antibiotic sensitivity pattern of bacterial isolates from the catheterized patients who are admitted in intensive care units and urology wards which guides for the effective management of such cases.

\section{Methods}

A present study was a prospective study, conducted at Microbiology department, New Hospital Medical Collage, Kota ,Rajasthan for a period of 6 months (January 2019 to June 2019) after ethical permission (Number F3()/acad$2 / 2019 / 1706$ ). The study population was 210 ICU inpatients catheterized by indwelling urinary catheter. Urinary catheter care bundle was implemented among all catheterized patients as per healthcare infection control practices advisory committee guidelines $^{[5]}$

Inclusion criteria- Patient must meet 1, 2 and 3 below

1. Patient had an indwelling urinary catheter that had been inserted after admission \& is in place for $>2$ days after admission, either: Still present on the date of event or removed the day before the date of event.

2. Patient has at least one of the following signs or symptoms: - fever $\left(>38.0^{\circ} \mathrm{C}\right)$ -suprapubic tendernes $\cdot$ cost vertebral angle pain or tenderness $\bullet$ urinary urgency $\bullet$ urinary frequency $\bullet$ dysuria

3. Patients who has given consent

\section{Exclusion Criteria}

1. Patients who already have sub-acute/chronic Urinary tract infections prior to admission

2. Patients who has not given consent.

\section{Collection and Processing of Samples}

Clinical history comprising of signs and symptoms such as fever, suprapubic tenderness, costovertebral angle tenderness or any other related to UTI is obtained from the patients. After obtaining proper consent, about $10 \mathrm{ml}$ of Urine sample is aspirated from indwelling catheter near the urethral site/ sampling port, under aseptic precautions which was transported to the microbiology laboratory for immediate processing.

Processing of specimens in laboratory: The urine samples were subjected to direct wet mount and culture using semi-quantitative standard loop technique. $^{[10]}$ Inoculation was done on MacConkey agar and blood agar. These plates were incubated aerobically at $37^{\circ} \mathrm{C}$ for $18-24$ hours. On the next day, colony count done for organisms showing growth and colony count $\geq 10^{5}$ was taken significant. Discrete bacterial isolates thus obtained were subjected to Gram staining, hanging drop preparation, other necessary tests including biochemical tests for further identification. The species identification of bacterial and fungal isolates was done based on standard laboratory procedures ${ }^{[11]}$. Kirby-Bauer disc diffusion method was adopted for antimicrobial susceptibility testing using appropriate antimicrobial discs as per CLSI guidelines. ${ }^{[12]}$

\section{Results}

A total 210 urine sample from catheterized patients were obtained. Of the total 210 patients $121(57 \%)$ were male and $89(42 \%)$ were female patients. Coming to microscopic examination, out 
of 210 urine samples, 33 samples showed the evidence of pus cells and or micro-organisms. Following the culture ,170 (81\%) was sterile and $33(16 \%)$ samples showed growth of which 31 were bacterial and 2 showed fungal growth. 7 samples have shown insignificant growth on culture.

Off the 31 bacterial isolates, most common isolate was E. coli in 23 (74\%) cases, followed by Klebsiella species in 5 (17\%) cases. Other Gramnegative bacteria such as, Acinetobacter were found in $2(6 \%)$ cases \& among gram positive bacteria, Enterococcus spp. was seen in $1(3 \%)$ cases. The 2 fungal isolates obtained were candida albicans. (Table 1)

Table 1: spectrum of isolates obtained in CAUTI

\begin{tabular}{|l|c|c|}
\hline S.No & Organism & No of isolates \\
\hline 1 & E.coli & 23 \\
\hline 2 & Klebsiella Sp. & 5 \\
\hline 3 & Acinetobactor & 2 \\
\hline 4 & Enterococcus & 1 \\
\hline 5 & Candida albicans & 2 \\
\hline \multicolumn{2}{|c|}{ Total } & 33 \\
\hline
\end{tabular}

Table 2 shows that the incidence of UTI was significantly higher as the days of catheterization increased.

\section{Table 2}

\begin{tabular}{|l|c|}
\hline No of days of catheterisation & Presence of UTI \\
\hline $2-4$ & 4 \\
\hline $5-7$ & 8 \\
\hline $7-14$ & 21 \\
\hline Total & 33 \\
\hline
\end{tabular}

In our study, males (55\%) have more incidence of CAUTI as compared to females (45\%).

Age distribution in CAUTI confirmed cases is shown in figure 1

Figure 1

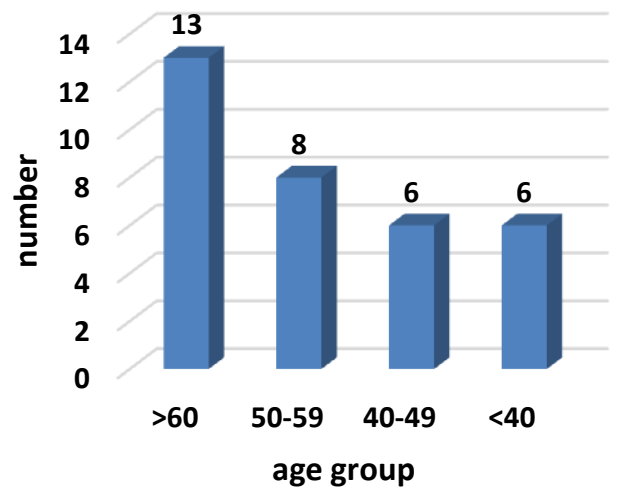

Table 3: Antimicrobial susceptibility pattern of Enterobacteriaciae

\begin{tabular}{|l|c|c|c|}
\hline Antimicrobial drug & Sensitive & $\begin{array}{c}\text { Intermediately } \\
\text { sensitive }\end{array}$ & Resistant \\
\hline Ampicillin/sulbactum & 6 & 4 & 18 \\
\hline $\begin{array}{l}\text { Amoxicillin/clavulanic } \\
\text { acid }\end{array}$ & 9 & 2 & 17 \\
\hline Azithromycin & 5 & - & 23 \\
\hline $\begin{array}{l}\text { Cefoperazone/ } \\
\text { sulbactum }\end{array}$ & 13 & - & 15 \\
\hline Ceftazidime & 20 & 1 & 7 \\
\hline $\begin{array}{l}\text { Ceftazidime/ } \\
\text { Clavulinic acid }\end{array}$ & 28 & - & - \\
\hline Colistin & 25 & 1 & 2 \\
\hline Cotrimoxazole & 8 & 1 & 19 \\
\hline Gentamicin & 15 & 1 & 12 \\
\hline Imipenam & 13 & & 15 \\
\hline Netilmicin & 18 & 1 & 9 \\
\hline Nitrofurointoin & 20 & 4 & 4 \\
\hline Norfloxacin & 5 & & 23 \\
\hline $\begin{array}{l}\text { Piperacillin/ } \\
\text { Tazobactam }\end{array}$ & 10 & & 18 \\
\hline
\end{tabular}

Table 3 shows high level of resistance of to commonly used drugs for UTI such as norfloxacin (82\%), azithromycin $(81 \%)$, ceftazidime $(68 \%)$, cotrimoxazole $(68 \%)$ and piperacillin-tazobactam (64\%). Among Enterobacteriaceae 25\% isolates were extended spectrum $\beta$ lactamase producers. Colistin was preserved as a reserve drug.

Table 4: Antimicrobial susceptibility pattern of nonfermenting bacteria (acenetobactor)

\begin{tabular}{|l|c|c|c|}
\hline Antimicrobial drug & Sensitive & $\begin{array}{c}\text { Intermediately } \\
\text { sensitive }\end{array}$ & Resistant \\
\hline Ampicillin/sulbactum & 1 & & 1 \\
\hline Cefepime & 1 & & 1 \\
\hline Cefotaxime & & & 2 \\
\hline Colistin & 1 & 1 & \\
\hline Ceftazidime/tazobactam & 1 & & 2 \\
\hline Ciprofloxacin & & & 1 \\
\hline Cotrimoxazole & 1 & & 1 \\
\hline Gentamicin & 1 & & 2 \\
\hline Meropenem & 1 & 1 & \\
\hline Norfloxacin & 1 & & \\
\hline Nitrofurantoin & & & \\
\hline $\begin{array}{l}\text { Piperacillin/ } \\
\text { Tazobactam }\end{array}$ & 2 & & \\
\hline
\end{tabular}

Antimicrobial pattern of acinetobactoris shows that most effective antibiotic was piperacillin/ tazobactam (100\% sensitive) and least effective antibiotic agents were cefotaxime, nitrofurantoin \& ciprofloxacin. 
Table 5: Antimicrobial susceptibility pattern of Enterococcus species

\begin{tabular}{|l|c|c|c|}
\hline $\begin{array}{l}\text { Antimicrobial } \\
\text { drug }\end{array}$ & Sensitive & $\begin{array}{c}\text { Intermediately } \\
\text { sensitive }\end{array}$ & Resistant \\
\hline Ampicillin & - & - & 1 \\
\hline Ciprofloxacin & - & - & 1 \\
\hline Doxycycline & - & - & 1 \\
\hline Fosfomycin & - & - & 1 \\
\hline Gentamicin & - & - & 1 \\
\hline Levofloxacin & 1 & - & - \\
\hline Linezolid & 1 & - & - \\
\hline Nitrofurantoin & 1 & - & - \\
\hline Vancomycin & 1 & - & - \\
\hline
\end{tabular}

Enterococcus speciesisolate was sensitive to linezolid, vancomycin levofloxacin and nitrofurantoin. Vancomycin was preserved as a reserve drug.

\section{Discussion}

CAUTI is the common HAI among ICU patients. Several risk factors are associated with the development of CAUTI which include prolonged intra urinary catheter dwell time, lengthy hospital stay, female gender, neurological issues and comorbid conditions in critical care patients. ${ }^{[13]}$

Overall 16\% incidence of CAUTI was found in present study. Study by Kakaria BA et al in Maharashtra, 2018 has found overall incidence of UTI $31 \%$ in catheterized patients. ${ }^{[14]}$ Vinoth $\mathrm{M}$ et al., found that incidence of CAUTI was $20 \%$ in their study. ${ }^{[15]}$

Incidence of CAUTI in our study was found comparatively less than other studies. Possible reason for that may be strict adherence to hand hygiene among staff and doctors, proper implementation of catheter care bundle, increased attention to avoid unnecessary urinary catheterization, wherever possible short term catheterizations was done, use of gowns and gloves by health care workers\& proper environmental decontamination by effective disinfectants.

As advancing age is one of the predisposing host factors for development of CAUTI, the largest age group included in our study is $>60$ years of age (40\%) while $24 \%$ of the patients were between 50 - 60 years of age (Fig. 1).
Usually female gender is another significant risk factor in many studies. The increased risk among women is probably due to anatomic makeup (ie short length urethra, approximation of urethral and anal opening) causing an easier access of the perineal flora to the bladder along the catheter ${ }^{[13]}$ However, in our study males were predominantly affected. This might be due to multiple factors. A higher number of male samples are received as compared to female samples. Also most of the cases in our study are of advanced age and male are prone to obstructive urinary lesion especially from benign prostate hypertrophy, Ca prostate and stricture associated with advanced age.

In the present study, among total CAUTI patients, $12 \%$ of patients were catheterised for 2-4 days duration, 24\% have catheter from 5 to 7 days and $64 \%$ have catheterisation from 1 to 2 weeks. This clearly shows risk of developing CAUTI increases with days of catheterization. This is similar to the study done by Sangamithra et $\operatorname{al}(2017)^{[16]}$ and Vinoth $M$ et al., (2017). ${ }^{[15]}$ So ,unnecessary catheterization should be avoided wherever possible short term catheterizations must be done.

In present study E. coli (69\%) was found the most common isolate among all microorganisms isolated. Kakaria et al (40\%), Sanghmitra et al (36\%) also found E. coli as most isolated organism $^{[14,16]}$. After E. coli, klebsiella species (16\%) was second most common isolate. Study by kakaria et al also shows klebsiella as second most common uropathogen with isolation rate $18 \%$ [18\%].

Both commensal and uropathogenic E. coli (UPEC) strains colonize the large intestines of humans but UPEC strains primarily causes UTI. The reason for E.coli being the most common isolate in CAUTI is presence of several virulence factors like mannose-resistant hemagglutinins, $\mathrm{P}$ fimbriae, adhesins, biofilm formation, hemolysin, $\mathrm{K}$ antigens, and aerobactin ${ }^{[17]}$.

The high resistance rate among the isolates observed in our study may be part due to the design of our study as it involve patients from 
ICUs. These patients generally undergo various empiric antimicrobial treatment and are, therefore, prone to develop infections by multidrug resistant pathogens.

\section{Conclusion \& Prevention}

CAUTI has low prevalence $16 \%$ in our hospital with most common pathogen being Escherichia coli. The risk of CAUTI increases with advancing age, longer duration of catheterizations. Prevention is the main step against CAUTI. Emphasis should be made on appropriate use and early removal of catheters, aseptic insertion, the maintenance of a closed urinary drainage system. Hand washing should be done immediately before and after manipulation of catheter site or apparatus. The catheter should be inspected frequently to ensure there is no obstruction to flow of urine. Usage of antimicrobial agents in suspected cases of CAUTI may be withheld in ICUs till microbiology reports are made available unless absolute need for empirical therapy is required in order to avoid emergence of resistant strains. Hospital-wide surveillance program and appropriate catheter care protocols should be developed and implemented from evidence based protocol. Emphasis should always be given on good catheter management rather than use of prophylaxis to reduce incidence of CAUTI

\section{Bibliography}

1. Clark, A. Remarks on catheter fever. Lancet (1883). ii:1075-1077.

2. Beeson, P. B. The case against the catheter. Am J Med (1958).

3. Haley, R, Culver, D, White, J, Morgan, W. M, \&Emori, T. G. The nationwide nosocomial infection rate: A new need for vital statistics. Am J Epidemiol (1985).

4. Kamat US, Fereirra A, Motghare DD, Kulkarni MS. Epidemiology of hospital acquired urinary tract infections in a medical college hospital in Goa. Indian J Urology 2009; 25(1):76-80.
5. NATIONAL CENTRE FOR DISEASE CONTROL Directorate General of Health Services Ministry of Health \& Family Welfare Government of India Draft version 2017

6. Gokula RR, Hickner JA, Smith MA. Inappropriate use of urinary catheters in elderly patients at a Midwestern community teaching hospital. Am J Infect Cont. 2004;32(4):196-9.

7. Saint S, Lipsky BA, Goold SD. Indwelling urinary catheters: a one-point restraint Ann Intern Med. 2002;137(2):125-7.

8. Smith J. Indwelling catheter management: From habit-based to evidence-based practice. Ostomy Wound Management. 2003;49:34-45.

9. Kang CI, Chung DR, Son JS, Ko KS, Peck $\mathrm{KR}$, Song JH, et al. Korean network for study of infectious diseases. Clinical significance of nosocomial acquisition in urinary tract-related bacteremia caused by gram-negative bacilli. Am J Infect Cont. 2011;39(2):135-40.

10. Collee JG, Duguid JP, Fraser AG, Marmion BP, Simmons A. Laboratory strategy in the diagnosis of infective syndromes. In: Collee JG, Fraser AG, Marmion BP and Simmons A, editors. Mackey and McCartney Practical Medical Microbiology. 14thed. Churchill Livingstone, Elsevier;2006. 53-94.

11. Forbes BA, Sahm DF, Weissfeld AS. Bailey and Scott's Diagnostic Microbiology. 12th ed. Philadelphia; Mosby Elsevier; 2007.

12. Clinical and Laboratory Standards Institute (CLSI). Performance standards for antimicrobial susceptibility testing, 25th informational supplement M100-S25. Wayne, PA, USA: CLSI; 2015.

13. leticakriegel AS, salmasian $\mathrm{H}$, Vawdrey DK et al. identifying the risk factors for catheter associated UTI; a large cross 
sectional study of six hospitals. BMJ open 2019; 9; e022137.doi;101136/2018.

14. Kakaria BA et al. Int J Res Med Sci. 2018 May;6(5):1730-1733

15. Vinoth $M$ et al. Int J Res Med Sci. 2017 Jun;5(6):2367-2372.

16. Sangamithra, V., Sneka, Shabana Praveen and Manonmoney. 2017. Incidence of Catheter Associated Urinary Tract Infection in Medical ICU in a Tertiary Care Hospital. Int. J. Curr. Microbiol. App.Sci. 6(4): 662-669. doi: https://doi.org/10.20546/ijcmas.2017.604.0 81.

17. Benton, J., J. Chawla, S. Parry, and D. Stickler. 1992. Virulence factors in Escherichia coli from urinary tract infections in patients with spinal injuries. J. Hosp. Infect. 22:117-127. 